\title{
A new tool for life cycle inventories of agricultural machinery operations
}

\author{
Daniela Lovarelli, Jacopo Bacenetti, Marco Fiala \\ Department of Agricultural and Environmental Sciences, Production, Landscape, \\ Agroenergy, University of Milan, Italy
}

\begin{abstract}
The interest in environmental assessments about agricultural processes is fast growing and asking for new tools for accurate impact evaluations. The methodology commonly used to go through these studies is the life cycle assessment, of which the inventory phase (life cycle inventory, LCI) is an essential step. For studies focusing on agricultural productions, the completion of LCI is particularly complex: taking into account the pedo-climatic and mechanical operative variability is evidently difficult. However, the prediction of the environmental impact of mechanical operations caused by the agricultural sector is essential to quantify the impact categories for which it is responsible.

A new tool, ENVIAM, was developed to complete LCI to guarantee the availability of local data that describe the mechanical and pedo-climatic conditions occurring in the Po Valley area and widely applicable as well. It calculates mechanical power requests, directly consumed inputs (i.e., fuel, lubricant) and material consumption of a productive system by taking into account soil texture, specific machinery operations and coupling solutions as defined by the user. A subdivision of working time and defined engine load have been considered to calculate fuel consumption; with regard to outputs, exhaust gases emissions from internal combustion engines have been assessed by evaluating the emissive stages of belonging as stated by the EU Directive. A case study was also performed to highlight the differences that occur when an analysis is fulfilled in a context with features different from the average, and resulted in significant variations for the inventory. In more details, a comparison was carried out both with Ecoinvent database and within ENVIAM. With regard to fuel consumption, by chang-
\end{abstract}

Correspondence: Daniela Lovarelli, Department of Agricultural and Environmental Sciences, Production, Landscape, Agroenergy, University of Milan, via G. Celoria 2, 20133 Milan, Italy.

Tel.: +39.02.50316694 - Fax: +39.02 .50316845 .

E-mail: daniela.lovarelli@unimi.it

Key words: Agricultural mechanisation; life cycle inventory; pedo-climatic variability; environmental impact assessment.

Received for publication: 4 June 2015.

Accepted for publication: 13 December 2015.

(C) Copyright D. Lovarelli et al., 2016

Licensee PAGEPress, Italy

Journal of Agricultural Engineering 2016; XLVII:480

doi:10.4081/jae.2016.480

This article is distributed under the terms of the Creative Commons Attribution Noncommercial License (by-nc 4.0) which permits any noncommercial use, distribution, and reproduction in any medium, provided the original author(s) and source are credited. ing the soil texture, the analysis showed a range between $64 \%-184 \%$ for sandy and clay soils, respectively, if compared with medium texture ones. With this tool, local contexts defined either as real or as optimised coupling solutions can be investigated to assess their environmental impact.

\section{Introduction}

The recent interest in environmental assessments about agricultural processes is fast growing and asking for tools to make possible accurate sustainability evaluations (Bengoa et al., 2014; Meul et al., 2014; Notarnicola et al., 2015). Being agriculture one of the most impacting sectors (IPCC, 2006), the adoption of methodologies able to guarantee the accurateness and quality of environmental assessments is needed (Jensen et al., 1997; Kerkhof, 2012; Goedkoop et al., 2013). The environmental impact assessment of agro-mechanical operations is an essential component to quantify these responsibilities: they not only concern acidification and eutrophication (e.g., application of fertilisers) but also climate change and resources depletion, as main cause of the use of fossil fuels and raw materials (IPCC, 2006; Notarnicola et al., 2015).

The most useful and emergent methodology to quantify the environmental impacts of several productive sectors is the life cycle assessment (LCA) methodology, characterised by a complete analysis approach made of four phases (ISO standard 14040 series) (ISO, 2006). The phases are: i) goal and scope definition; ii) life cycle inventory (LCI); iii) environmental impact assessment and iv) interpretation. The LCA application to the agricultural sector highlighted some methodological problems because it was developed mainly for industrial processes. In agricultural processes, unlike for industrial ones, inputs and outputs of the system are not always easily measured (Brentrup et al., 2004; Dyer and Desjardins, 2003; Ossés de Eicker et al., 2010; Bacenetti et al., 2012; Bengoa et al., 2014). In particular, to obtain primary data (measured), regarding the several emissions sources (in air, water and soil), expensive measures (in terms of money and time) are needed. To overcome this concern, some databases encompassing also the most common agricultural operations are available (e.g., Ecoinvent, the Danish LCA food, the EU and DK input and output database, the agri-footprint database). For agricultural operations, the use of secondary data deriving from these databases is the most applied solution; nevertheless, it is only a partial solution that can introduce uncertainty. The main reason is that, given the database complexity, not all or not always, LCA practitioners are aware of the exact composition of the selected process.

Moreover, each mechanical operation process involved in the databases refers to average conditions and parameters in terms of soil (texture, water content), field shape and slope, distance from the farm and tractors and implement features (e.g., mass, lifespan, annual working time). Therefore, these processes are valid in their related context, but the applicability in different ones should not be taken for 
granted. When a process from a database is used, it should be modified using inventory data assessed taking into account local pedo-climatic conditions. The availability of a tool that builds a reliable LCI for agricultural operations in the different pedo-climatic contexts, reduces the inaccuracies related to the uncritical use of database processes and can help when an agricultural operation has not been already inserted in databases.

This study relates to the Po Valley area located in Northern Italy, that represents a very important area for Italian agriculture. Common crop production systems consist of cereals (e.g., maize, rice and winter crops; ISTAT, 2011) for which usual local mechanical operations are carried out (e.g., tillage, crop management, irrigation, drying). By adopting Ecoinvent (Ecoinvent, 2015) in this context, data often result too much simplified and/or totally missing because average European assumptions are not valid (Hansson et al., 2001; Nemecek and Kägi, 2007; Ossés de Eicker et al., 2010; Fiala and Bacenetti, 2012; Bacenetti et al., 2014; Niero et al., 2015; Tendall and Gaillard, 2015). The lack is especially evident when the study focuses on field conditions different from those defined by Ecoinvent. In order to solve these concerns, a tool has been developed to support the completion of an inventory reliable for local conditions.

The aim of this study is the description of the tool, called ENVIAM, ENVironmental Inventory of Agricultural Machinery operations that has been developed with the goal of supporting the realisation of a locally reliable inventory about agricultural machinery. The inventory is needed to define inputs and outputs referred to the functional unit to make possible the subsequent phase of the life cycle impact assessment. In addition, the perspicuity of results makes LCA practitioners aware of the inventory data in study.

\section{Materials and methods}

\section{ENVIAM description}

ENVIAM is the first release of a tool implemented in a MS Office Excel spreadsheet structured to ease the logical steps to follow. It was developed with the goal of assessing a specific inventory valid in the Italian context and applicable in a wide range of different operative conditions and alternatives (e.g., machines, soils with different texture).

ENVIAM achieves an accurate quantification of the mechanical parameters (tractor engine power and machinery specific features) and of diesel fuel consumed that most affect agricultural field operations. It performs calculations with usual mechanical knowledge but inputs and outputs of the operations are calculated through refined awareness. Local inputs (e.g., fuel, lubricants and other materials) and outputs (e.g., exhaust gases emissions) are calculated using both primary (measured) and secondary (context-specific) data. Results can be obtained both for a single operation and for more of them, as the methodology can be retraced for each operation in study. In the end, the results referred to the functional unit ( $1 \mathrm{ha}$ ) or to the total studied field surface can be used to fulfil the LCI phase of an LCA study.

For what concerns the system boundary of each mechanical operation, the analysis includes materials that compose machines, fuel and lubricant and the emission of the main exhaust gases from the combustion in tractor engines.

With regard to the implementation, the user-friendly interface was specifically researched to facilitate the understanding and choice of the parameters. Eleven worksheets were realised and can be discerned in 3 main groups: i) databases (tractor and machinery); ii) support (tables, timing definition, linkage worksheet); iii) calculations (mechanical calculations, fuel and exhaust gases emissions and results).

All worksheets need the user intervention in parameters selection, according to the features characterising the case study. Firstly, two databases of tractors and implements are furnished to have a wide range of labels and models among which to choose the needed machinery. Then, the mechanical operation to carry out must be selected from a list. Currently, the main field operations for crops production typically carried out in the Po Valley are enlisted.

As regards the supporting tables, parameters are given. They must be specifically selected to calculate the requested tractor engine power. Checks are made through tests and the user is directed in all choices.

Finally, ENVIAM calculates fuel consumption (FC), exhaust gases emissions (EM), lubricants and materials consumed during each agricultural machinery operation and results can be related both to the whole operation in study and only to the functional unit (FU), which is $1 \mathrm{ha}$. By retracing the same steps for each operation, a whole production chain or part of it can be analysed.

Comparisons to investigate the influence on outputs can be made among: i) optimal (best coupling solution of tractor and implement) and other coupling alternatives. Optimal coupling means that the tractor is selected from the database considering the most closed engine power to the one calculated from the tool. Other coupling alternatives can result by the selection of a tractor with too much high (or low) engine power. This choice influences the final outcomes; ii) similar agricultural machines for carrying out a mechanical operation. In this case it means that the same operation is carried out comparing two or more alternative implements; iii) machines adoptable for carrying out alternative operations. Different machines are used for alternative operations in order to analyse the solutions and choose the best alternative.

\section{Databases worksheets}

Two databases have been realised; the first is currently composed of 100 tractors (records), classified per label and model and for each of them, mechanical features are enlisted besides (fields). It was fulfilled employing the official Organisation for Economic Co-operation and Development (OECD) reports, Code 2, approved in 2010-2012.

The second database currently lists more than 400 implements (records), on the basis of the operations commonly carried out in the Po Valley for crops production e.g., maize, winter cereals). The fields structure is similar to the former database and is reported in Figure 1: label and model, typology of power absorbed [e.g., power take off (PTO) or no PT0, towed or carried implement], absorbed engine power, working width and depth (whether necessary), hopper volume (for seed, chemicals and harvested grains), load capacity (for organic and mineral spreaders and for trailers), mass composition (steel, glass, rubber, etc.), total mass and engine features specific for self-propelled machinery.

\section{Support worksheets}

In the first support worksheet, a wide number of tables are given, distinguishing among different soil types or among agricultural machinery operations. Information is included for adherence and rolling coefficients, forward speed, power surplus coefficient, physical lifespan of tractors, implements and tires, engine load and specific soil resistance. The user must select one of the available values per table, according to the selected operation and to the specific field features.

A second worksheet is related to timings sub-division defined by Reboul (1964; CIOSTA - Comité International d'Organisation Scientifique du Travail en Agriculture). In this section, all the working time components defined in the literature (e.g., effective work, turns, arrangements, fillings) are reported and the user must measure them 
on field to fill in the table. Because field shape and size lead to different working time - and LCI -, it is an essential data to measure on field. The measured data are used to compose the total working time (T; h) of the machinery operation (Eq. 1). However, not all of them are compulsory. For instance, during rotary harrowing, neither filling nor emptying time is needed; therefore the input value is 0 .

$$
\begin{aligned}
& T=\sum T_{i}=T E F+T A V+T A S+T A C+ \\
& T P L+T M E+T M I+T R E+T P H+T R I
\end{aligned}
$$

where:

$T_{i}$ (h) is the single temporal component.

TEF is effective working time, TAV turns at headlands, TAS fillings/emptying, TAC field maintenance, TPL implement arrangement on field, TME and TMI avoidable and unavoidable downtime (respectively), TRE worker rest, TPH implement arrangement on farm, TRI transfers.

\section{Calculation worksheets}

They are needed for the quantification of:

- Inputs and outputs for each timing component. In particular, they are:

i) fuel consumption; and ii) exhaust gases emissions $\left(\mathrm{CO}, \mathrm{CO}_{2}, \mathrm{NO}_{\mathrm{X}}\right.$, $\mathrm{HC}$ and $\mathrm{PM}$ ). With regard to emissions, it must be underlined that the model quantifies the main ones, but that many other gases are emitted, due both to the production of the machines and to that of fuel and lubricant. This section is strictly dependent on tractor engine power, which is the main variable to be quantified. It is calculated according to the selected implement, to traction force and to power requirement. According to the resulting engine power request, the tractor is chosen from the database among those with a similar power to the calculated (Figure 2). In more details, the tractors' database is fulfilled with a wide number of tractors that cover a wide range of engine power (between 30.6-314.1 kW); therefore, the database has enough options to find in any case a tractor with a similar engine power to the calculated request. Indeed, when a similar engine power is not selected, results are affected as follows (Figure 3 ): when a lower engine power is chosen, the tests in support of engine power request calculation (adherence, lifting capability and longitudinal stability) result negative, meaning that the tractor cannot afford the working conditions; on the opposite, when a too much high engine power is chosen, results are negatively affected because the tractor works with a much lower engine load than it should in optimal conditions and, as a consequence, fuel consumption and exhaust gases emissions are subjected to change. Different outputs from ENVIAM result in different inputs for the environmental impacts assessment through LCA software.

- Inputs and outputs that depend on other variables (time, lifespan,

Table 1. Minimum and maximum engine load values attributed

\begin{tabular}{|c|c|c|}
\hline Working time & & \\
\hline & Min & $\operatorname{Max}$ \\
\hline Effective time & 50 & 100 \\
\hline Turns time & 15 & 40 \\
\hline Refilling/emptying & 0 & 2 \\
\hline On-field maintenance & 0 & 2 \\
\hline Assume the arrangement setting & 0 & 2 \\
\hline Avoidable downtime & 0 & 2 \\
\hline Unavoidable downtime & 0 & 2 \\
\hline Rest time & 0 & 2 \\
\hline On-farm maintenance & 0 & 2 \\
\hline Transfer time & 30 & 100 \\
\hline
\end{tabular}
to each working time ( $i$ - timing).

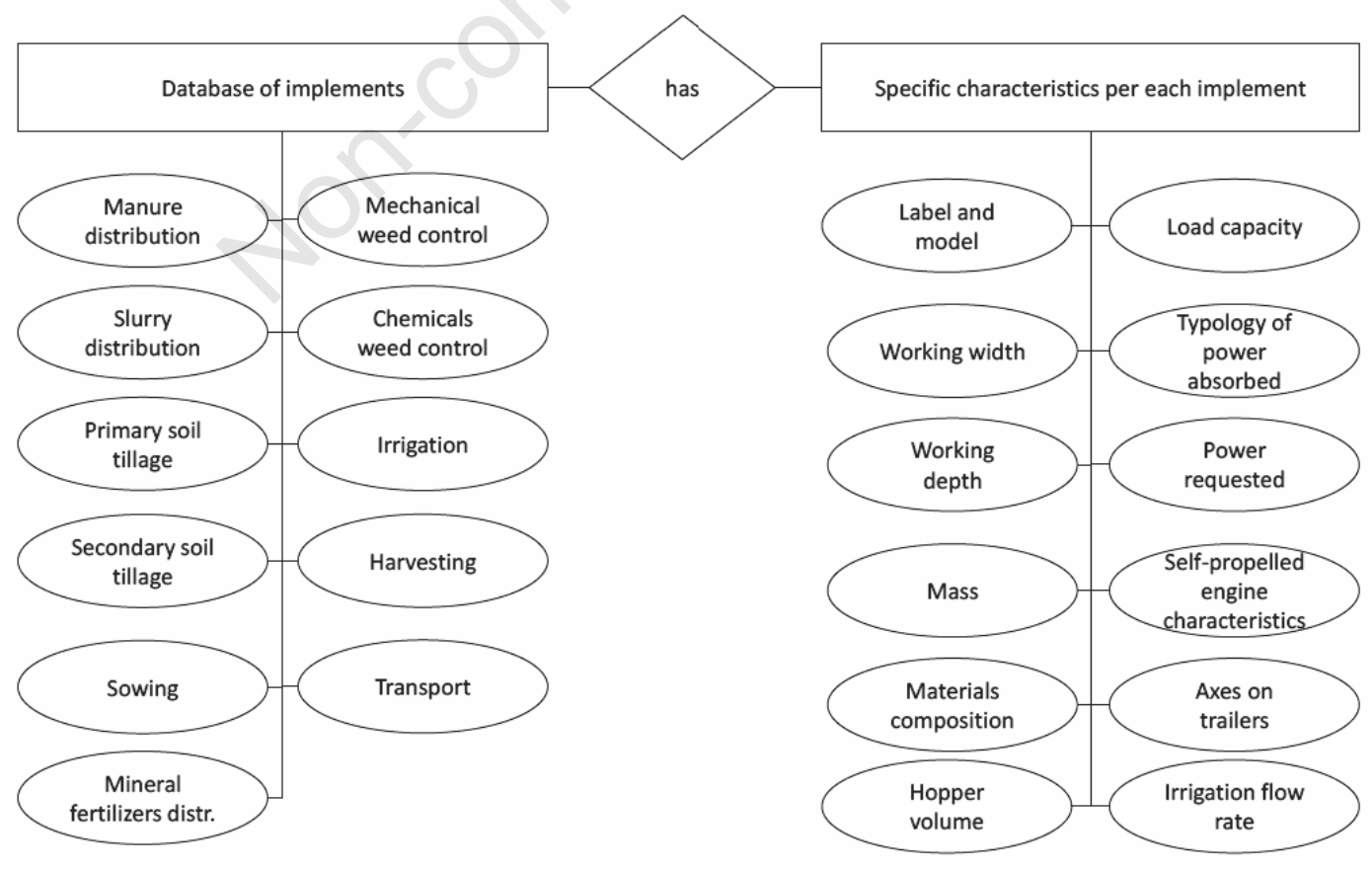

Figure 1. Implements database includes agricultural machinery operations and each implement has records for specific technical characteristics. 
masses, etc.) are: i) materials consumption; ii) lubricant consumption; iii) input products for the fulfilment of operations (e.g., organic and mineral fertilisers, irrigation water). ENVIAM calculates inputs and outputs expressed per field. However, they are also reported to the FU: materials consumption $\left(\mathrm{kg} \cdot \mathrm{ha}^{-1}\right)$, fuel and lubricant consumption $\left(\mathrm{kg} \cdot \mathrm{ha}^{-1}\right)$ and exhaust gases emissions $\left(\mathrm{g} \cdot \mathrm{ha}^{-1}\right)$.

\section{Methodology definition}

Engine load $(\lambda)$

The engine load $(\lambda ; \%)$ is calculated as in Eq. 2 :

$\lambda=\frac{P m}{P m_{M A X}}$

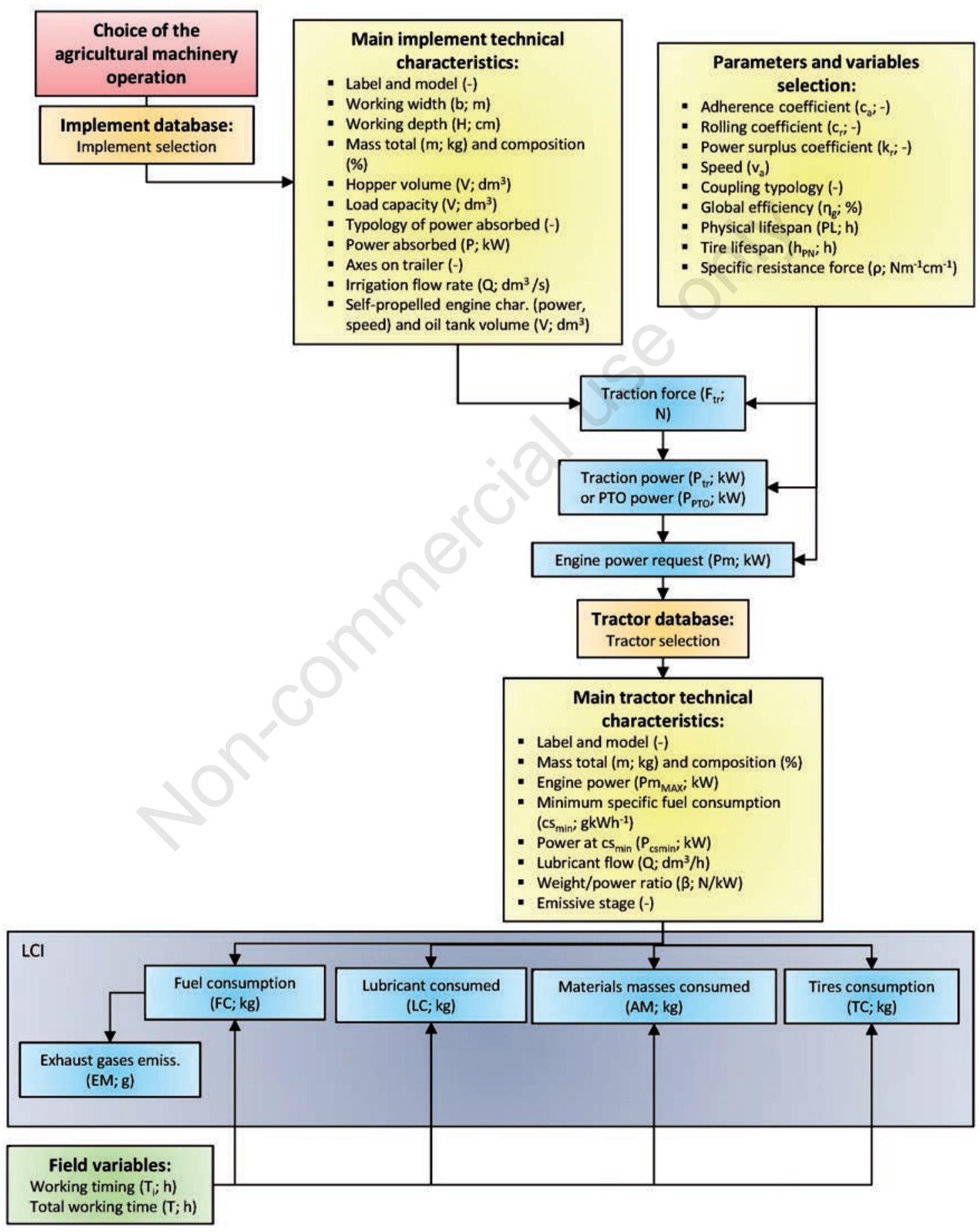

Figure 2. Representation of the steps: from the choice of the agricultural machinery operation to the achievement of results (ENVIAM outputs and life cycle inventory inputs). 
where:

$P m(\mathrm{~kW})$ is the engine power absorbed by the implement;

$P m_{\text {MAX }}(\mathrm{kW})$ is the tractor engine power.

According to literature, most of tractors run at $50-70 \%$ of $\mathrm{Pm}_{\text {MAX }}$ during their whole life cycle (Janulevičius et al., 2013a, 2013b; Kim et al., 2013; Lacour et al., 2014). However, $\lambda$ significantly varies during the operation and strongly influences FC.

Therefore, in ENVIAM, each operation was built composing fractions of working time (Reboul, 1964) in which different average $\lambda$ occur. Table 1 shows the $\lambda$ range that was assumed for all the timing components ( $i$ - timings) and it is recommended for optimal (or nearly optimal) coupling between tractor and implement; however, it varies according to coupling and to the operation. Usually, while effectively working on field the $\lambda$ is high, but it is not during the whole operation, since $\lambda$ can be much different during other activities that compose the working time (e.g., during turns, maintenance and arrangement settings, etc.). Low $\lambda$ can occur during turns (the field shape affects the number of turns and, as a consequence, the total turning time characterised by that $\lambda$ ) and refilling/emptying (e.g., manure spreading, pesticides spraying). In these cases, the tractor is on but not working (engine at idle), therefore $0 \%$ is advised. About $2 \%$ is attributed to those conditions in which only low power is used for the execution of the operation (e.g., hydraulic power). Higher values are attributed to more power-requesting operations.

\section{Fuel consumption}

According to literature, there are several methods to calculate FC (Grisso et al., 2004; Lazzari and Mazzetto, 2005; Serrano et al., 2007; Janulevičius et al., 2013a; Sørensen et al., 2014).

ENVIAM takes into account the specific fuel consumption (cs; $\mathrm{g} \cdot \mathrm{kWh}^{-1}$ ), which is defined as the mass of fuel consumed per mechanical energy unit produced $(\mathrm{kW} \cdot \mathrm{h})$. cs and the engine load $(\lambda ; \%)$ are used to calculate the fuel consumption (FC; kg) applying Lazzari and Mazzetto (2005). The fuel consumption occurring during the $i$ - timing $\left(\mathrm{FC}_{\mathrm{i}} ; \mathrm{kg}\right)$ is calculated applying Eq. 3:

$F C_{i}=\sum c s_{i} \cdot P m_{M A X} \cdot \lambda_{i} \cdot T_{i}$

where:

$c s_{i}\left(\mathrm{~g} \cdot \mathrm{kWh}^{-1}\right)$ is the specific fuel consumption of the $i$ - timing;

$\lambda_{\mathrm{i}}(\%)$ is the $i$ - engine load.

Total fuel consumption (FC; $\mathrm{kg}$ ) is the summation of all $\mathrm{FC}_{\mathrm{i}}$ that compose the operation (Eq. 4).

$$
F C=\sum F C_{i}
$$

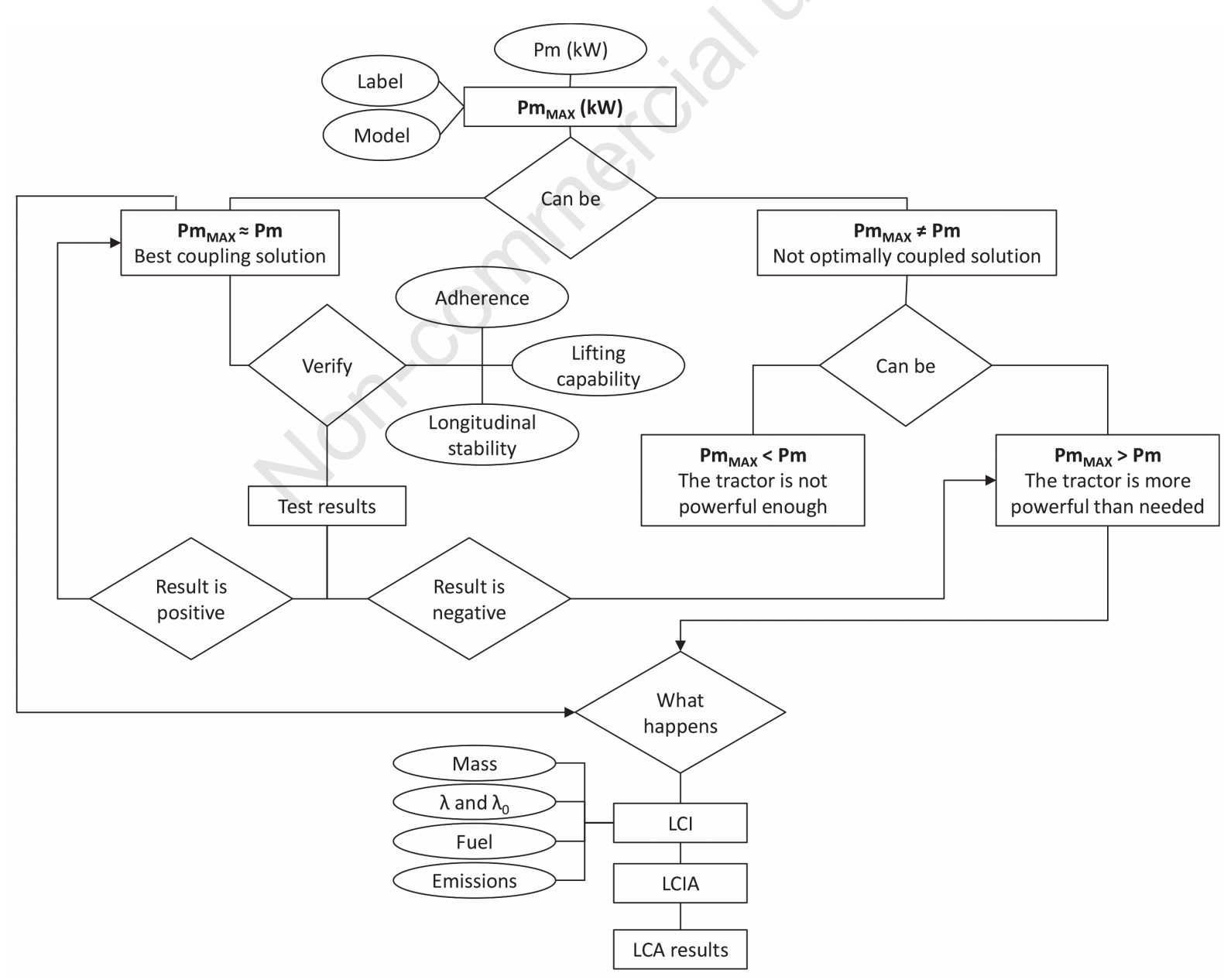

Figure 3. Effects of engine power $\left(\mathrm{Pm}_{\mathrm{MAX}}\right)$ on the coupling. 


\section{Exhaust gases emissions}

EM are formed during fuel combustion in internal combustion engines and depend on: i) age of the engine; ii) engine power; and iii) engine load with its related dynamic changes.

The year in which the engine was built is crucial, since the emissive limits to which it belongs strongly influence the levels of exhaust gases emissions, as defined by applying the Emissive Standards got from the EU Directive 97/68/EC (and following amending ones: Directive 2010/26/EU, Directive 2010/22/EU) and the ISO standard 8178-4 cycle C1 (European Commission, 1998; ISO, 2007; European Commission, 2010a, 2010b).

Different methods are proposed in literature to assess EM in tractors engines (Hansson et al., 2001; Nemecek and Kägi, 2007; Schäffeler and Keller, 2008; Lindgren et al., 2010; Janulevičius et al., 2013a, 2013b; Kim et al., 2013). However, only Schäffeler and Keller (2008) make available a tool accessible according to the EU Directive and, consequently, to the engine of the specific tractor present in ENVIAM database. The EU Directive dictates engine producers to respect the emissive limits for the main exhaust gases that are $\mathrm{CO}_{2}, \mathrm{CO}, \mathrm{NO}_{\mathrm{X}}, \mathrm{HC}$ and PM. However, during combustion in internal engines, many other gases are produced, but are not quantified in this tool.

In ENVIAM, EM (g) of $\mathrm{CO}_{2}, \mathrm{CO}, \mathrm{NO}_{\mathrm{x}}, \mathrm{HC}$ and $\mathrm{PM}$ are calculated according to these authors. Except for $\mathrm{CO}_{2}$, exhaust gases emissions are quantified as follows:

$$
E M_{i}=\sum E M_{S P} \cdot P m_{M A X} \cdot \lambda_{i} \cdot T_{i} \cdot C F_{1} \cdot C F_{2} \cdot C F_{3}
$$

where:

$E M_{i}$ (g) is the emission of the $i$ - timing;

$E M_{S P}$ is the specific limit of each exhaust gas $\left(\mathrm{g} \cdot \mathrm{kWh}^{-1}\right)$;

$C F_{1}, C F_{2}$ and $C F_{3}$ are correction factors.

By considering different $\lambda_{\mathrm{i}}$ and $\mathrm{T}_{\mathrm{i}}$, the total emissions of each exhaust gas are calculated (Eq. 6).

$$
E M=\sum E M_{i}
$$

As concerns $\mathrm{CO}_{2}$ from diesel engines, $3.150 \mathrm{~g}_{\mathrm{CO} 2} / \mathrm{g}_{\mathrm{FUEL}}$ is the factor employed (Schäffeler and Keller, 2008). Once the European Stage of engine belonging is inserted, according to the year of engine production, the proper emission value is picked out. Table 2 shows a numerical example with a tractor that shows different emissions at different working timings.

\section{Amount of machinery and materials}

ENVIAM evaluates tractors and implements material consumption (AM; kg) during the operation:

$$
A M=\frac{m}{P L} \cdot T
$$

where:

$m(\mathrm{~kg})$ is the mass (tractor/implement);

$P L$ (h) is the physical lifespan.

PL is the maximum amount of time the machine can work and depends on the typology of work and on the materials needed and used. Average values (Bodria et al., 2006) are suggested but the user can insert different ones according to his study.

In literature, there is an evident lack of data about agricultural machinery composition and manufacturers do not even make these data available. The only accessible are given by Ecoinvent v3 and by few manufacturers' environmental declarations of different machines (e.g., Volvo: http://www.volvoce.com/constructionequipment/corporate/en$\mathrm{gb} /$ environment/publications/Pages/publications.aspx). As regards tractors $\left(\mathrm{AM}_{\mathrm{TR}} ; \mathrm{kg}\right)$, materials masses consumed were calculated considering tractor masses as defined by OECD Reports (2010-2012) and tractor lifespans by Bodria et al. (2006); their subdivision was established as reported by Nemecek et al. (2011). For implements ( $\mathrm{AM}_{\mathrm{OM}}$; $\left.\mathrm{kg}\right)$, several and significant differences among machines for different operations were evident, therefore $\mathrm{AM}_{\mathrm{OM}}$ was calculated according to information obtained through interviews with experts.

Materials distinction is applied to those tractor materials that are part of the machine for the whole lifespan (partial wear); those continuously consumed are calculated separately (e.g., lubricants, tire sets).

\section{Lubricant consumption}

Lubricants substitution in tractors is made according to maintenance schedules, which suggest to substitute engine lubricants on average every $300-400 \mathrm{~h}$ of work $\left(\mathrm{T}_{\mathrm{r}} ; \mathrm{h}\right)$, whereas in other tractor components the time is longer (gearbox, hydraulic lift, PTO, transmission components).

Tractor lubricant consumption (LC; kg) was calculated with (Eq. 8).

$$
L C=\frac{V}{T_{r}} \cdot \gamma \cdot T
$$

where:

$V\left(\mathrm{~m}^{3}\right)$ is the lubricant volume;

$T_{r}$ (h) is the retention time (time during which the lubricant remains exploitable in engine/other components);

$\gamma\left(\mathrm{kg} \cdot \mathrm{m}^{-3}\right)$ is the lubricant density.

Moreover, also agricultural machinery LC was reported, as assumed valid for appropriate maintenance schedules and resulting from interviews with experts.

\section{Tire sets consumption}

\begin{tabular}{|c|c|c|c|c|c|c|c|}
\hline \multicolumn{2}{|c|}{$\begin{array}{l}\text { Timings } \\
(\mathrm{Ti} ; \mathrm{h})\end{array}$} & $\begin{array}{l}\text { Engine load } \\
\qquad(\lambda ; \%)\end{array}$ & $\begin{array}{c}\text { CO emiss. } \\
\left(\mathrm{EM} ; \mathrm{g} \cdot \mathrm{ha}^{-1}\right)\end{array}$ & $\begin{array}{l}\text { HC emiss. } \\
\left(\mathrm{EM} ; \mathrm{g} \cdot \mathrm{ha}^{-1}\right)\end{array}$ & $\begin{array}{l}\mathrm{NO}_{\mathrm{X}} \text { emiss. } \\
\left(\mathrm{EM} ; \mathrm{g} \cdot \mathrm{ha}^{-1}\right)\end{array}$ & $\begin{array}{l}\text { PM emiss. } \\
\left(\mathrm{EM} ; \mathrm{g} \cdot \mathrm{ha}^{-1}\right)\end{array}$ & $\begin{array}{l}\mathrm{CO}_{2} \text { emiss. } \\
\left(\mathrm{EM} ; \mathrm{g} \cdot \mathrm{ha}^{-1}\right)\end{array}$ \\
\hline TEF & $1.2 \mathrm{~h}$ & $73 \%$ & 194.98 & 45.22 & 676.53 & 37.25 & $60,877.63$ \\
\hline TAV & $0.12 \mathrm{~h}$ & $30 \%$ & 8.02 & 1.86 & 27.82 & 1.53 & 4852.87 \\
\hline TAC & $0.04 \mathrm{~h}$ & $1 \%$ & 0.09 & 0.02 & 0.31 & 0.02 & 103.72 \\
\hline TPH & $0.08 \mathrm{~h}$ & $1 \%$ & 0.18 & 0.04 & 0.62 & 0.03 & 207.43 \\
\hline TRI & $0.06 \mathrm{~h}$ & $40 \%$ & 5.35 & 1.24 & 18.55 & 1.02 & 2640.07 \\
\hline
\end{tabular}

No data were found in literature about tire sets real lifespan except

Table 2. Example of tractor $\left(\mathbf{P m}_{\mathrm{MAX}}=96.4 \mathrm{~kW}\right)$ belonging to emissive Stage 2 that shows at different timing components a different engine load and consequently different exhaust gases emissions for a ploughing operation.

TEF, effective time; TAV, turns time; TAC, on-field maintenance; TPH, on-farm maintenance; TRI, transfer time. 
for Ecoinvent database (Nemecek and Kägi, 2007), which only showed a single average value assumed valid for all tractors and conditions $(2500 \mathrm{~h})$.

To compensate for the lack, tractor tire sets lifespan ( $h_{\mathrm{PN}}$; $\left.h\right)$ was assumed from interviews with experts according to the prevailing tractor working activity (Table 3 ). Attributing different lifespan values permitted to distribute rubbed-off rubber during an adequate time set.

To calculate tire sets mass ( $\left.\mathrm{m}_{\mathrm{PN}} ; \mathrm{kg}\right)$, a coefficient $\mathrm{k}_{\mathrm{PN}}(0.0975$ $\mathrm{kg}_{\mathrm{PN}_{\mathrm{N}}} \cdot \mathrm{kg}_{\mathrm{TR}}{ }^{-1}$; Nemecek and Kägi, 2007) was employed. It is an empiric ratio between tires mass and tractor mass, validated through measurements on-site as well.

The rubber composing the tire (TC; kg) was calculated with Eq. 9 and distributed along tractor lifespan.

$$
T C=\frac{m_{P N}}{h_{P N}} \cdot \frac{1}{k_{h}} \cdot T
$$

where:

$m_{P N}(\mathrm{~kg})$ is the tire sets mass;

$h_{P N}(\mathrm{~h})$ is tire sets lifespan;

$k_{h}(\%)$ is the ratio between tire sets lifespan and tractor lifespan.

\section{Coupling calculations}

Mechanical operations were distinguished in order to take into account the specific power requests. The distinction concerns:

- The typology of implement coupled, so implements are: i) towed (T); or ii) carried (P).

- The operations, which are generally distinguished in: i) primary and secondary soil tillage; ii) crop management; iii) stationary; and iv) transport.

The power absorbed by the implement (Pm; $\mathrm{kW})$ depends on the tractor global efficiency $\left(\eta_{g} ; \%\right)$ that characterises the operation; values for $\eta_{\mathrm{g}}$ are obtained from Bodria et al. (2006) and depend on power dissipations that vary between $2 \mathrm{WD}$ and $4 \mathrm{WD}$ and among the typologies of power request.

As concerns these last, the distinction is among: i) stating (F): the work is carried out in a stationary position (e.g., irrigation, hydraulic woodcutter); ii) towing (T): the implement is only towed by the tractor (e.g., transport); iii) towing and PT0 (T+PT0): the implement needs both traction force and PTO power (e.g., organic fertilisers spreading, hay baling); iv) carrying (P): the implement is carried and only traction force is needed (e.g., ploughing, fixed teeth harrowing); v) carrying and PTO (P+PT0): the implement is carried and PT0 power is needed (e.g., rotary harrowing, sowing, pesticides spraying, mineral fertilisers spreading).

With regard to both primary and secondary soil tillage operations, required engine power differs as function of soil texture as well; the specific soil resistance $\left(\rho ; \mathrm{N} \cdot \mathrm{m}^{-1} \cdot \mathrm{cm}^{-1}\right)$ values, specific per soil texture and per machinery operation, were taken from literature (Bodria et al., 2006). Similarly, adherence and rolling coefficients originate from Bodria et al. (2006). Adherence coefficient is needed in adherence test and rolling coefficient in traction force calculation.

To calculate Pm:

$$
P m=\frac{\mathrm{Ftr} \cdot v_{a}}{3600 \cdot \eta_{g}}
$$

where:

$F_{t r}(\mathrm{~N})$ is traction force - calculated by the tool; $v_{a}\left(\mathrm{~km} \cdot \mathrm{h}^{-1}\right)$ is average forward speed;

$\eta_{g}(-)$ is tractor global efficiency - defined by the user in the parameters section.

To calculate Pm for PTO power operations:

$$
P m=\frac{P_{P T O}}{\eta_{g}}
$$

where:

$P_{\text {PTO }}(\mathrm{kW})$ is the specific power demanded from the PTO available in the implements' database. Once Pm is calculated, power surplus coefficient $\left(\mathrm{k}_{\mathrm{r}} ; \%\right.$ - range: $\left.1.05-1.30 \cdot \mathrm{Pm}\right)$ is taken into account, with the purpose of considering potential higher power requests if hard working conditions occur. $\mathrm{k}_{\mathrm{r}}$ is selected from the specific table.

Tests

After the tractor selection, tests are made to verify the adequateness of the choice as shown in Figure 4 as well:

- Adherence test (Fiala, 2001; Bodria et al., 2006): to verify that the tractor can overcome external resistance forces. Parameters are already available in ENVIAM: i) tractor mass $\left(\mathrm{m}_{\mathrm{TR}} ; \mathrm{kg}\right)$; ii) tractor weight/power ratio $\left(\beta ; \mathrm{N} \cdot \mathrm{kW}^{-1}\right)$; iii) adherence coefficient $\left(\mathrm{c}_{\mathrm{a}}\right)$. Verify whether adherence (Ad; N) - calculated by multiplying adherence weight $\left(\mathrm{G}_{\mathrm{a}} ; \mathrm{N}\right)$ and adherence coefficient $\left(\mathrm{c}_{\mathrm{a}}\right)$ - is higher than $F_{\text {tr }}(N) . G_{a}$ for $2 \mathrm{WD}$ tractors is the weight on the rear axle, whereas for $4 \mathrm{WD}$ tractors is the total weight. Whether $\mathrm{Ad}<\mathrm{F}_{\mathrm{tr}}$, ballasting $\left(\mathrm{G}_{\mathrm{z}}\right.$; $\mathrm{kg}$ ) is compulsory.

$$
G_{z}=\frac{\left(F_{t r}-A d\right)}{g \cdot c_{a}}
$$

However, if too much ballast is necessary $\left(\mathrm{G}_{\mathrm{z}} \geq 0.3 \cdot \mathrm{m}_{\mathrm{TR}}\right)$ a more powerful (and heavier) tractor is advised.

- Lifting test (ASABE, 1997): for carried implements, to verify that the tractor hydraulic lift is capable of lifting the implement. This test concerns: i) maximum lifted weight $\left(\mathrm{Gs}_{\mathrm{MAx}} ; \mathrm{N}\right)$; ii) implement mass ( $\left.\mathrm{m}_{\mathrm{OM}} ; \mathrm{kg}\right)$; iii) length of parallels on three point hitch till tractor rear axle (br; m); iv) implement length till its centre of gravity (bs; m); v) reference distance $b_{\text {rif }}$ (equal to $0.610 \mathrm{~m}$ ).

$G s_{M A X}>\frac{m_{O M} \cdot g \cdot(b s+b r)}{(0.610+b r)}$

br and bs were already inserted in ENVIAM, however, the user can use specific values. This is especially valid for bs, as it differs according to implement length. As for br, the value $0.80 \mathrm{~m}$ was selected, being valid for a wide range of tractors.

Table 3. Lifespan of tire sets according to the prevailing tractor activity.

\begin{tabular}{llc} 
Prevailing field operation & \multicolumn{2}{c}{ Tire sets lifespan (h) } \\
& Min & Max \\
Primary soil tillage & 4000 & 5000 \\
Secondary soil tillage & 5000 & 6000 \\
\hline Crop management & 6500 & 8000 \\
Transport & 2000 & 3000 \\
\hline Mixed work & 3000 & 7000 \\
\hline
\end{tabular}


- Longitudinal stability test (D.lgs. 81/08, attachment 5; Italian Regulation, 2008): to verify that the tractor will not overturn longitudinally. Needed data already available in ENVIAM are: i) tractor and implement masses $\left(\mathrm{m}_{\mathrm{TR}}\right.$; $\mathrm{kg}$ and $\mathrm{m}_{\mathrm{OM}}$; $\left.\mathrm{kg}\right)$; ii) tractor pitch distance (bp; $\mathrm{m}$ ); iii) length of parallels on three point hitch till tractor rear axle (br; m); iv) implement length till its centre of gravity (bs; m). Italian law D.lgs $81 / 08$, attachment 5 states that $20 \%$ of the weight of the tractor plus the worker (assumed standard weight equal to 75 $\mathrm{kg}$ ) considering bp, br and bs must be higher than the weight of the implement (Italian Regulation, 2008):

$$
m_{O M}<\frac{0.2 \cdot\left(m_{T R}+m_{O M}\right) \cdot b p}{b r+b s}
$$

When this condition is not verified, tractor mass is not suitable to such an implement and either ballasting or another tractor or implement must be selected.

\section{Output worksheet}

The output worksheet is divided in two parts. The first includes mechanical data of tractor, implement and operation as consequence of coupling. Data selected in the other worksheets are picked up and for the major part of them, the user plays a basic role: whether the selected value is correct, the test results positive (cell in green background); where no range is reported, the user inserts a value that can be either the same as the calculated or a different one. In addition, a column is devoted to checks. To complete the analysis and if required for the operation, the user can include input materials (IN; $\mathrm{kg}$ - e.g., amounts of fer- tilisers, pesticides, seed, irrigation water, etc.); however this is not compulsory. The second part is composed of the results of the agricultural machinery employment. Therefore, it is reported the consumed/emitted amount (total and related to $1 \mathrm{ha}$ ) of: i) fuel (FC; $\mathrm{kg}$ and $\left.\mathrm{kg} \cdot \mathrm{ha}^{-1}\right)$; ii) lubricant (LC; $\mathrm{kg}$ and $\left.\mathrm{kg} \cdot \mathrm{ha}^{-1}\right)$; iii) tractor and implement (AM; $\mathrm{kg}$ and $\mathrm{kg} \cdot \mathrm{ha}^{-1}$ ) both the total and the internal material composition; iv) tire set rubber (TC; $\mathrm{g}$ and $\left.\mathrm{g} \cdot \mathrm{ha}^{-1}\right)$; v) input products (IN; $\mathrm{kg}$ and $\mathrm{kg} \cdot \mathrm{ha}^{-1}$ ); vi) emissions into air due to exhaust gases (EM; $\mathrm{g} \mathrm{CO}_{2}$, g CO, g NO , g $\mathrm{HC}, \mathrm{g} \mathrm{PM}$ and $\left.\mathrm{g} \cdot \mathrm{ha}^{-1}\right)$.

\section{Results}

\section{Goal and structure of the case study}

In order to explain how ENVIAM works and the achievable results, a case study concerning ploughing operation was realised. In the following sections, two comparisons are described. First, an explanation of the outputs got from ENVIAM is reported. In more details, the outputs were calculated for three cases in which the type of soil was variable, while implement, working time and all the mechanical parameters not influenced by the soil were the same. The first comparison was made between ENVIAM ploughing process related to a medium texture soil and the same process present in Ecoinvent v3. This analysis aimed at evaluating whether, in the same working conditions, the two tools made feasible the achievement of similar results. The second comparison was made within ENVI$\mathrm{AM}$, analysing the consequences of soil variability on the assessment of mechanical choices (e.g., tractor engine power) and on the consumption of inputs and emission of combustion exhaust gases.

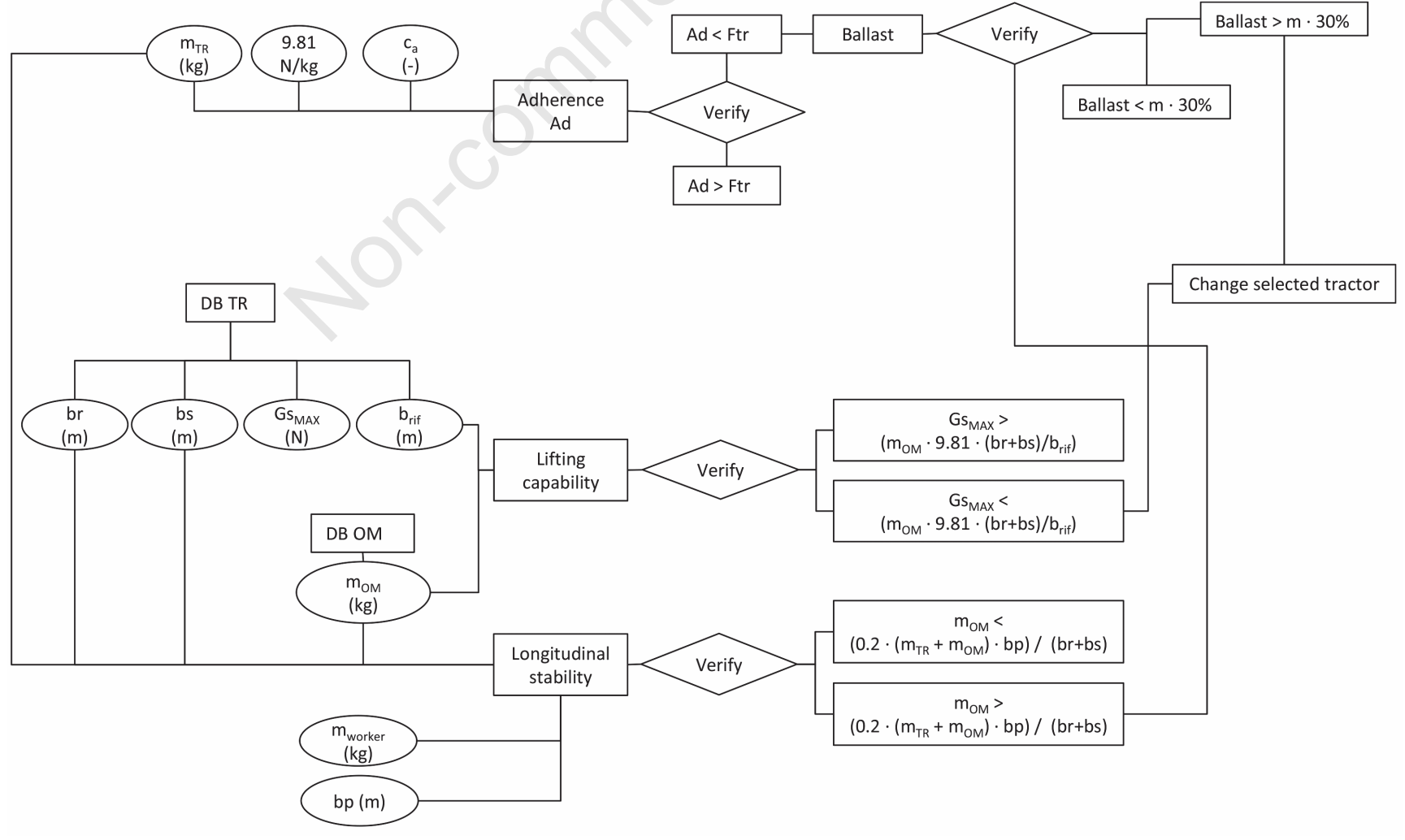

Figure 4. Tests carried out to verify adequateness of the selected tractor. Tests are adherence, lifting capability and longitudinal stability. 


\section{Description of ENVIAM outputs}

With regard to ENVIAM, a commercial three ploughshares mouldboard plough, mass $1600 \mathrm{~kg}$, was selected from the database to carry out the operation. The soil texture was considered variable, therefore three conditions were assessed: i) sandy soil (SA); ii) medium texture soil (MT); iii) clay soil (CL). For each soil condition, soil resistance $(\rho)$ values were for SA $\rho=300 \mathrm{~N} \cdot \mathrm{m}^{-1} \cdot \mathrm{cm}^{-1}$, for MT $\mathrm{r}=550 \mathrm{~N} \cdot \mathrm{m}^{-1} \cdot \mathrm{cm}^{-1}$ and for CL $\rho=1100 \mathrm{~N} \cdot \mathrm{m}^{-1} \cdot \mathrm{cm}^{-1}$. Consequently, power required to carry out ploughing differed and different tractors were needed. For all the three cases, the selected parameters are reported in Table 4.

A tractor with similar $\mathrm{Pm}_{\text {MAX }}$ was selected from the database verifying adherence (whether needed quantifying ballasting), lifting and stability. With regard to working time composition and engine load, a subdivision is reported in Table 5. The working time was measured on three fields with different soil texture worked by the same operator and the same implement, but with different tractors. Figure 5 reports the followed logical steps. The total time was the same for all the three cases: the effective working time was the same, since working width and speed were constant. As for the other timing components (TAV, TAC, TPH and TIR), time requirements were measured on field and resulted analogous, since the operator was the same and the field shape was similar, in order to assess comparable working conditions. Similarly, engine load was calculated during the effective working time $\left(\lambda_{\mathrm{TEF}}\right)$ and differed in each case according to $\mathrm{Pm}$ and $\mathrm{Pm}_{\mathrm{MAx}}$. On the other components of working time, $\lambda$ was assumed the same in all three cases.

The total working time was $\mathrm{T}=1.61 \mathrm{~h} \cdot \mathrm{ha}^{-1}$ and Figure 6 shows time subdivision. Table 6 reports the results of FC, EM, amounts of lubricant, tire and machines consumed (for both tractors and plough) of the three cases evaluated with ENVIAM.

\section{Comparison with Ecoinvent process}

In order to compare results of ENVIAM with those of Ecoinvent database, it must be considered that Ecoinvent only considers an average value for medium texture soils (Figure 7).

Therefore, a comparison with ENVIAM could be done only in this condition. The FC in medium texture conditions calculated from ENVIAM was $25.7 \mathrm{~kg} \cdot \mathrm{ha}^{-1}$ and was similar to that from Ecoinvent $(26.1$ $\mathrm{kg} \cdot \mathrm{ha}^{-1}$ ), with a difference lower than $2 \%$. Even if in average conditions the variability between the two data sources was small, it can be explained by the calculation method. Fuel consumption was quantified taking into account the engine load in each timing, the specific fuel consumption of the selected tractor and an effective fieldwork capacity defined according to the operative conditions.

With regard to exhaust gases emissions, stronger differences were evident. In particular, for $\mathrm{CO}, \mathrm{NO}_{\mathrm{x}}$ and $\mathrm{CO}_{2}$ the difference from ENVIAM was $23 \%, 180 \%$ and $101 \%$, respectively; HC and PM were not comparable to Ecoinvent data. Nevertheless, ENVIAM adopts the recent European Stage emissive standards; therefore, the normative limits expressed in the EU Directive are respected.

Since no consideration could be made on lubricants and tire sets, as ENVIAM and Ecoinvent do not have the same aggregation of results, only amount of machines consumed was compared. This last, however, was relevant, being $218 \%$ and $170 \%$ higher in Ecoinvent than in ENVIAM. The effective duration of the operation and machines lifespan mainly explained these results.

\section{Comparison with different soil textures}

In order to examine the differences occurring by varying soil texture, the medium texture ploughing operation resulting from ENVIAM was compared with the one in sandy and clay soils. Selected options are reported in Table 7. Soil type influences $\mathrm{Pm}_{\text {MAX }}$ needed to carry out the operation, and, consequently, FC and EM. In particular,
Table 4. Selected input parameters for the case study.

\begin{tabular}{lcc} 
Parameter & Symbol & Value \\
Average speed & $\mathrm{V}_{\mathrm{a}}$ & $6.0 \mathrm{~km} \cdot \mathrm{h}^{-1}$ \\
Tractor global efficiency & $\eta \mathrm{g}$ & $56 \%$ \\
\hline Working width & $\mathrm{L}$ & $1.35 \mathrm{~m}$ \\
Working depth & $\mathrm{H}$ & $0.35 \mathrm{~m}$ \\
\hline Power surplus coefficient & $\mathrm{k}_{\mathrm{r}}$ & $20 \%$ \\
Tractor lifespan & $\mathrm{PL}_{T R}$ & $12,000 \mathrm{~h}$ \\
\hline Implement lifespan & $\mathrm{PL}_{\mathrm{OM}}$ & $2000 \mathrm{~h}$ \\
Tire sets lifespan & $\mathrm{h}_{\mathrm{PN}}$ & $4000 \mathrm{~h}$ \\
\hline
\end{tabular}

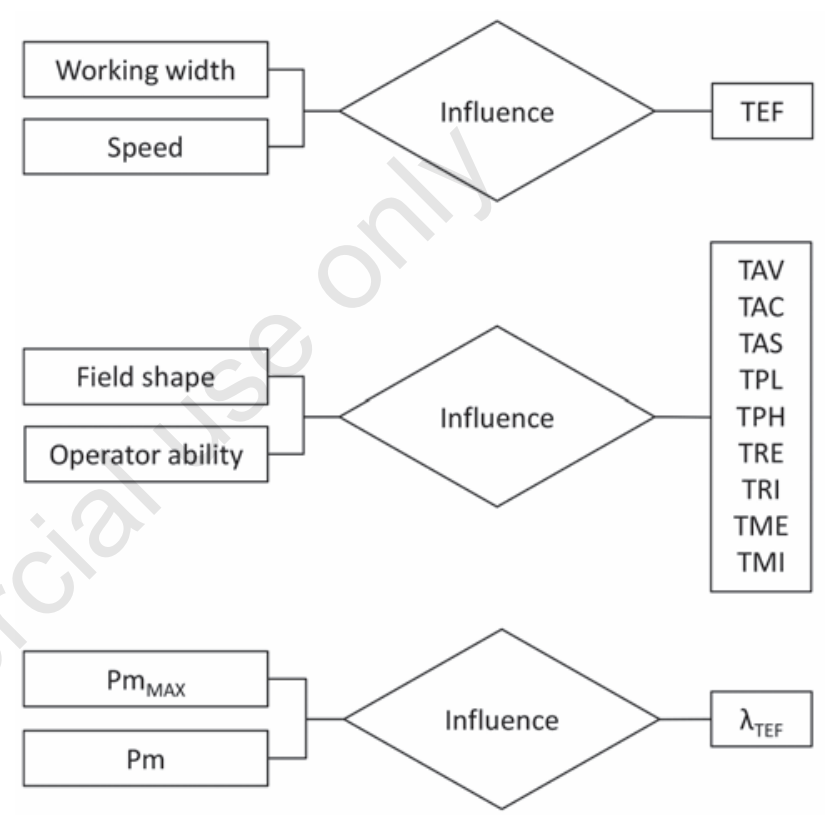

Figure 5. Sharing of the influence of mechanical and local parameters on working time and engine load $(\lambda)$. TEF, effective time; TAV, turns time; TAC, on-field maintenance; TAS, refilling/emptying; TPL, assume the arrangement setting; TPH, on-farm maintenance; TRE, rest time; TRI, transfer time; TME, avoidable downtime; TMI, unavoidable downtime.

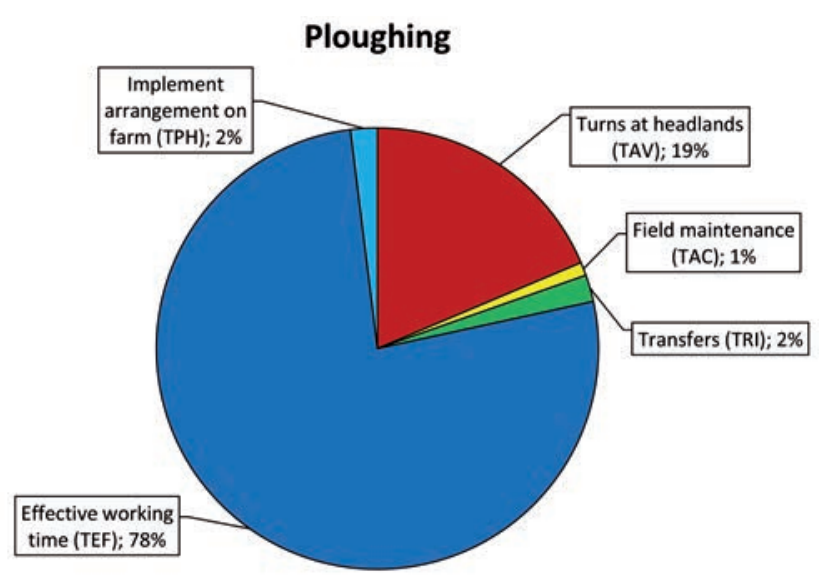

Figure 6. Time subdivision. 
FC for ploughing on a sandy soil resulted equal to $65 \%$ of the one occurring on a medium texture soil, while was equal to $187 \%$ for a clay soil. Exhaust gases emissions showed a similar behaviour as well, highlighting the lowest emissions on sandy soils and the highest on clay soils. The release of $\mathrm{CO}, \mathrm{HC}, \mathrm{NO}_{\mathrm{x}}$ and $\mathrm{PM}$ ranged between $45-46 \%$ for sandy soils when compared with medium texture ones. $\mathrm{CO}_{2}$, however, had a similar behaviour to $\mathrm{FC}$ in all soil conditions, being directly influenced by fuel consumed. On a clay soil, exhaust emissions from engine tractors during ploughing were 138\%, 198\%, $120 \%$ and $198 \%$, respectively for $\mathrm{CO}, \mathrm{HC}, \mathrm{NO}_{\mathrm{X}}$ and $\mathrm{PM}$ of medium texture case. With regard to the amounts of lubricants, tires and mate- rials consumed, the differences occurring among the three tractors (the plough was the same in the three cases), were due to $\mathrm{Pm}_{\text {MAX }}$ and to the selected tractor masses $(3552 \mathrm{~kg}, 5380 \mathrm{~kg}$ and $11,430 \mathrm{~kg}$, respectively for tractors employed on SA, MT and CL). In addition, comparing $\mathrm{FC}$ results with the average one from Ecoinvent database results are $64 \%$ and $184 \%$, respectively in sandy and clay conditions. Moreover, if not only the soil, but also the implement was varied, stronger differences could have taken place. As an example, with a 5 ploughshares mouldboard plough, total working time would have reduced to $1.29 \mathrm{~h} \cdot \mathrm{ha}^{-1}$, being wider the working width. FC in sandy, medium texture and clay soils would vary between $79-113 \%$; EM as

Table 5. Subdivision of time and engine load composing case study.

\begin{tabular}{|c|c|c|c|c|c|c|c|c|c|c|c|c|}
\hline \multicolumn{13}{|c|}{ Plough operation } \\
\hline Timing su & bdivision & TEF* & TAV & TAS & $\mathrm{TAC}$ & TPL & TME & TMI & TRE & TPH & TRI & Total \\
\hline $\mathrm{Ti}\left(\mathrm{h} \cdot \mathrm{ha}^{-1}\right)$ & 1.23 & 0.30 & 0.00 & 0.02 & 0.00 & 0.00 & 0.00 & 0.00 & 0.03 & 0.03 & 1.61 & \\
\hline$\lambda(\%)$ & $\begin{array}{l}73^{\mathrm{a}} \\
80^{\mathrm{b}} \\
79^{\mathrm{c}}\end{array}$ & 30 & 0 & 2 & 0 & 0 & 0 & 0 & 2 & 40 & - & \\
\hline
\end{tabular}

TEF, effective time; TAV, turns time; TAS, refilling/emptying; TAC, on-field maintenance; TPL, assume the arrangement setting; TME, avoidable downtime; TMI, unavoidable downtime; TRE, rest time; TPH, on-farm maintenance; TRI, transfer time. $* \lambda$ during TEF $\left(\lambda_{\text {TEF }}\right)$ varies depending on required power (Pm; $\left.k W\right)$. Being $\lambda$ quantified as function of Pm ${ }_{\text {MAx }}$ and Pm, the differences in $\lambda_{\text {TEF }}$ are justified by the lower/higher Pm and coupled tractor (different $\mathrm{Pm}$ MAX). ${ }^{\mathrm{a}} \lambda_{\text {TEF }}$ in SA (Pm is $43 \mathrm{~kW}$ ); ${ }^{\mathrm{b}} \boldsymbol{\lambda}_{\text {TEF }}$ in MT (Pm is $77 \mathrm{~kW}$ ); ${ }^{\mathrm{c}} \boldsymbol{\lambda}_{\text {TEF }}$ in CL (Pm is $\left.155 \mathrm{~kW}\right)$.

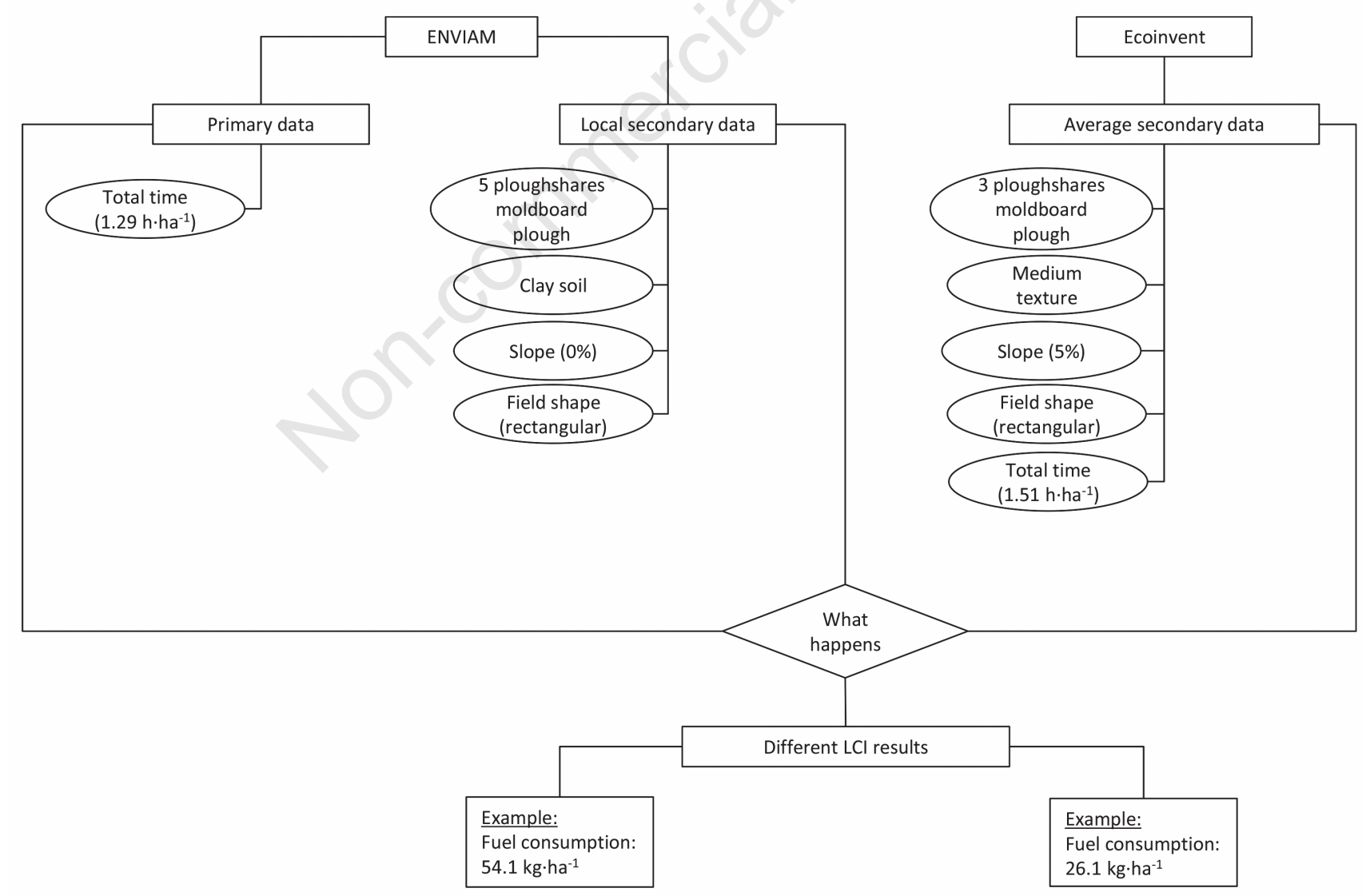

Figure 7. Data employment in ENVIAM and Ecoinvent including an example of the results about fuel consumption for a ploughing operation that is carried out considering local (ENVIAM) and average conditions (Ecoinvent). 
well, ranging between $64-143 \%$ for all exhaust gases considered, when compared with the ones with three ploughshares. In addition, since more powerful tractors would be needed, also higher amounts of materials, tires and lubricants would be consumed compared to the three-ploughshares, varying between $117 \%-145 \%$ for AM, 73\%$147 \%$ for LC and 117\%-166\% for TC.

\section{Discussion}

The development of ENVIAM tool brought to raise the awareness that a locally reliable instrument can be significantly helpful to realise a complete and trustworthy LCI. All calculations concerning tractor-implement coupling, tractor's engine power, implement's absorbed power, traction force and slipping are already available in literature. Researchers implemented many models in former years (Lazzari and Mazzetto, 1996; Rotz et al., 1983; Siemens et al., 1990; Haffar and Khoury, 1992; Søgaard and Sørensen, 1996; de Toro and Hansson, 2004). However, ENVIAM uses this typology of well-known calculations to develop a system working with the input databases available. In addition, goal of models developed in the $80 \mathrm{~s}$ and $90 \mathrm{~s}$ was the assessment of the economic cost of a coupling decision. On the opposite, goal of ENVIAM is the estimate of locally reliable inventory data used for subsequent environmental analyses of agricultural machinery operations. The calculation of inputs and outputs is obtained from the distinction of the operation in working timings, to each of which, a duration and a specific engine load are attributed. Therefore, the tool takes advantage of a well-known topic, to develop a useful calculation for nowadays-environmental issues. The case study highlighted that, comparing Ecoinvent ploughing process with ENVIAM one in the same soil conditions, low differences $(<2 \%)$ resulted about fuel consumption. However, they were not negligible with regard to other values, such as for $\mathrm{CO}$ and $\mathrm{NO}_{\mathrm{x}}$ emissions $(23 \%$ and $180 \%$, respectively), as well as for tractor and plough consumption (2.2 and 1.7 times higher for Ecoinvent for tractor and plough, respectively). With regard to the comparison carried out within ENVI$\mathrm{AM}$, several differences were highlighted considering the variables taken into account. In particular, the increase in soil resistance forces when the soil was sandy, of medium texture and clay, respectively, caused an increase in tractor engine power requirement, whose satisfaction involved an increase in fuel consumptions and exhaust gases emissions as well as in the materials consumed (bigger masses). About fuel consumption and exhaust gases emissions, the analysis of engine power and load made achievable the reach of higher accurateness. For emissions in particular, the use of the EU

Table 6. Results of fuel consumption, exhaust gases emissions, lubricant, tire and material consumption of the three tractors and plough obtained from the comparison among sandy, medium texture and clay soils in ENVIAM.

\begin{tabular}{|c|c|c|c|c|}
\hline $\begin{array}{l}\text { Parameters } \\
\text { Soil type }\end{array}$ & SA & ENT & CL & \\
\hline Tractor & Case IH JX 90 & Landini Landpower 135 T3 & Massey Ferguson 8650 & Plough \\
\hline $\mathrm{Pm}_{\operatorname{MAX}}(\mathrm{kW})$ & 58.8 & 96.3 & 196.8 & - \\
\hline $\mathrm{FC}\left(\mathrm{kg} \cdot \mathrm{ha}^{-1}\right)$ & 16.7 & 25.7 & 48.0 & - \\
\hline $\mathrm{CO}\left(\mathrm{g} \cdot \mathrm{h} \mathrm{a}^{-1}\right)$ & 423.5 & 914.5 & 1265.0 & - \\
\hline $\mathrm{HC}\left(\mathrm{g} \cdot \mathrm{ha}{ }^{-1}\right)$ & 16.5 & 35.6 & 70.3 & - \\
\hline $\mathrm{NO}_{\mathrm{x}}\left(\mathrm{g} \cdot \mathrm{ha}^{-1}\right)$ & 264.3 & 570.8 & 683.5 & - \\
\hline PM $\left(g \cdot h a^{-1}\right)$ & 2.0 & 4.4 & 8.7 & - \\
\hline $\mathrm{CO}_{2}\left(\mathrm{~g} \cdot \mathrm{ha}^{-1}\right)$ & $52,492.3$ & $80,815.4$ & $151,286.2$ & - \\
\hline Lubricant $\left(\mathrm{kg} \cdot \mathrm{ha}^{-1}\right)$ & 1.37 & 1.14 & 1.43 & 0.07 \\
\hline Tire sets $\left(g \cdot h a^{-1}\right)$ & 17.0 & 67.5 & 126.5 & 0.0 \\
\hline TR and OM, total $\left(\mathrm{kg} \cdot \mathrm{ha}^{-1}\right)$ & 0.48 & 0.71 & 1.51 & 1.27 \\
\hline
\end{tabular}

SA, sandy soil; MT, medium texture soil; CL, clay soil; FC, fuel consumption; TR, tractor; OM, implement.

Table 7. Results of the options selected in ENVIAM for analysing different soil type conditions.

\begin{tabular}{|c|c|c|}
\hline & & \\
\hline Soil typology & Sandy & Clay \\
\hline Tractor & Case IH JX 90 & Massey Ferguson 8650 \\
\hline WD & 4 & 4 \\
\hline $\mathrm{Pm}_{\text {MAX }}$ & $58.8 \mathrm{~kW}$ & $196.8 \mathrm{~kW}$ \\
\hline $\mathrm{Pm}$ & $42.2 \mathrm{~kW}$ & $154.7 \mathrm{~kW}$ \\
\hline $\mathrm{CS}_{\min }$ & $228 \mathrm{~g} \cdot \mathrm{kWh}^{-1}$ & $209 \mathrm{~g} \cdot \mathrm{kWh}^{-1}$ \\
\hline$\lambda_{\text {TEF }}$ & $73 \%$ & $79 \%$ \\
\hline$\lambda_{0}$ & $93 \%$ & $79 \%$ \\
\hline Emissive stage & IIIB & IIIB \\
\hline
\end{tabular}


Directive limits at different Stage of belonging, as well as specific engine loads at different working timings increases the reliability. Moreover, specific engine power, masses, working time and tractor lifespan mark the accurateness increase of outputs as well, which nowadays represents the main lack in Ecoinvent database. This is a particularly relevant issue for LCA studies that focus on agricultural systems. The reason is that studying a system, characterised by local pedo-climatic variables, but using average data will give misleading results. In fact, when the local features are taken into account, Ecoinvent shows inadequate outcomes. In the case study, the average was too much high for sandy soils and too much low for clay soils. Similar evaluations could also be carried out for analogous operations with wider or tinier implements (e.g., 5 ploughshares plough) and for other operations, e.g., harrowing, seeding, mineral and organic fertilising, harvesting. Even if this study aimed at describing a tool usable for the LCI phase, it is plausible to assume that the resulting differences are relevant for the assessment of the environmental impacts of agricultural machinery as well. If Ecoinvent was applied, at the end of an LCA study, an improper environmental impact assessment would be entailed. However, focusing on ENVIAM implementation, improvements can still be reached. In particular, the increase of operations in the database and a higher amount of machinery represent the main achievable enhancements, also developing other cultivation systems such as other open-field cultivations (e.g., potatoes, tomatoes), haying, orchards, as frequently appear in Italian and European cultivation contexts.

\section{Conclusions}

The attention on the environmental issues linked to agricultural machinery has recently increased enormously. Many databases and tools are available for research and commercial users to quantify the impacts on the environment of agricultural processes, but their reliability is poor when different pedo-climatic and mechanical conditions occur. In this study, the objective was to describe a tool developed to have those locally reliable inventory data necessary as inputs for subsequent LCA studies. ENVIAM was implemented using data about tractors and implements from literature, technical documentation and manufacturers. Databases of tractors and implements were inserted with the specific goal of having a wide range of ordinary machines, in order to adapt the software tool to the real farm conditions. Moreover, the completely mechanised field chain can be quantified by retracing the same modules for each operation. To show the effect of ENVIAM use on the inventory data, a comparison between its outputs and those from Ecoinvent v3 was done. It showed that average values present in Ecoinvent are applicable only in similar conditions, whereas when soil and implement have diverse features, the differences are not negligible. In conclusion, ENVIAM results not only in a support for LCIs, but is also a standalone tool. It can be applied to studies in which mechanical aspects are linked to environmental evaluations and in which environment-improvement possibilities must be compared and analysed.

\section{References}

ASABE (American Society of Agricultural and Biological Engineers). 1997. ASABE S349 - test procedure for measuring hydraulic lift capacity on agricultural tractors equipped with three-point hitch; published 1998-12-01. ASABE, St. Joseph, MI, USA.

Bacenetti J., Fusi A., Fiala M. 2014. Impatto ambientale delle oper- azioni agricole di campo: effetto della scelta della macchina operatrice e delle condizioni pedologiche. VIII Convegno Rete Italiana LCA, 19-20 June 2014, Florence, Italy.

Bacenetti J., González-García S., Mena A., Fiala M. 2012. Life cycle assessment: an application to poplar for energy cultivated in Italy. J. Agr. Eng. 43:72-8.

Bengoa X., Rossi V., Humbert S., Nemecek T., Lansche J., Mouron P. 2014. Methodological guidelines for the life cycle inventory of agricultural products. Version 2.0, July 2014. World Food LCA Database. Quantis and Agroscope, Lausanne and Zurich, Switzerland, pp. 1-79.

Bodria L., Pellizzi G., Piccarolo P. 2006. Il trattore e le macchine operatrici. Ed. Edagricole, Milano, Italy.

Brentrup F., Küsters J., Kuhlmann H., Lammel J. 2004. Environmental impact assessment of agricultural production systems using the life cycle assessment methodology. Eur. J. Agron. 20:247-64.

De Toro A., Hansson P.-A. 2004. Analysis of field machinery performance based on daily soil workability status using discrete event simulation or on average workday probability. Agr. Syst. 79:10929.

Dyer J.A., Desjardins R.L. 2003. Simulated farm fieldwork, energy consumption and related greenhouse gas emissions in Canada. Biosyst. Eng. 85:503-13.

Ecoinvent. 2015. Ecoinvent database. Available from: http://www.ecoinvent.org/database/ Accessed: 27 April 2015.

European Commission. 1998. Directive 97/68/EC of the European Parliament and of the Council of 16 December 1997 on the approximation of the laws of the Member States relating to measures against the emission of gaseous and particulate pollutants from internal combustion engines to be installed in non-road mobile machinery. In: Official Journal, L 59, 27/2/1998, pp 1-86.

European Commission. 2010a. Commission Directive 2010/22/EU of 15 March 2010 amending, for the purposes of their adaptation to technical progress, Council Directives 80/720/EEC, 86/298/EEC, 86/415/EEC and 87/402/EEC and Directives 2000/25/EC and 2003/37/EC of the European Parliament and of the Council relating to the type-approval of agricultural or forestry tractors. In: Official Journal, L 91, 10/4/2010, pp 1-68.

European Commission. 2010b. Commission Directive 2010/26/EU of 31 March 2010 amending Directive 97/68/EC of the European Parliament and of the Council on the approximation of the laws of the Member States relating to measures against the emission of gaseous and particulate pollutants from internal combustion engines to be installed in non-road mobile machinery. In: Official Journal, L 86, 1/4/2010, pp 29-47.

Fiala M. 2001. Esercizi di meccanica agraria. Ed. CUSL, Milano, Italy.

Fiala M., Bacenetti J. 2012. Model for the economic, energetic and environmental evaluation in biomass productions. J. Agr. Eng. 42:26-35.

Goedkoop M., De Oele M., Leijting J., Ponsioen T., Meijer E. 2013. SimaPro tutorial. Available from: https://www.presustainability.com/download/SimaPro8Tutorial.pdf

Grisso R.D., Kocher M. F., Vaughan D.H. 2004. Predicting tractor fuel consumption. Appl. Engine. Agric. 20:553-61.

Hansson P.A., Lindgren M., Norén 0. 2001. A comparison between different methods of calculating average engine emissions for agricultural tractors. J. Agr. Eng. Res. 80:37-43.

Haffar I., Khoury R. 1992. A computer model for field machinery selection under multiple cropping. Comput. Electron. Agric. 7:219-29.

IPCC (Intergovernmental Panel on Climate Change). 2006. Agriculture, forestry and other land use, vol.4. In: S. Eggleston, L. Buendia, K. Miwa K, T. Ngara, K. Tanabe (Eds.), IPCC Guidelines for National Greenhouse Gas Inventories. Institute for Global 
Environmental Strategies (IGES), Hayama, Japan. Available from: http://www.ipcc-nggip.iges.or.jp/public/2006gl/pdf/4_Volume4/V4_ 00_Cover.pdf

ISO (International Standardisation Organisation). 2006. ISO 14040:2006. Environmental management -- Life cycle assessment -- Principles and framework. Available from: http://www.iso.org/ iso/home/store/catalogue_tc/catalogue_detail.htm?csnumber $=37$ 456

ISO (International Standardisation Organisation). 2007. IS0 81784:2007. Reciprocating internal combustion engines -- Exhaust emission measurement -- Part 4: Steady-state test cycles for different engine applications. Available from: http://www.iso.org/ iso/home/store/catalogue_tc/catalogue_detail.htm?csnumber $=42$ 275

ISTAT (Italian Institute of Statistics). 2015. Censimento agricoltura. Available from: http://dati-censimentoagricoltura.istat.it/?lang=it Accessed: 27 April 2015.

Italian Regulation. 2008. Decreto Legislativo 9 aprile 2008, n. 81. Attuazione dell'articolo 1 della legge 3 agosto 2007, n. 123, in materia di tutela della salute e della sicurezza nei luoghi di lavoro. In: G.U. Ser. Gen. no. 101, 30/4/2008 - Suppl. Ord. no. 108.

Janulevičius A., Juostas A., Pupinis G. 2013a. Engine performance during tractor operational period. Energ. Convers Manage. 68:1119.

Janulevičius A., Juostas A., Pupinis G. 2013b. Tractor's engine performance and emission characteristics in the process of ploughing. Energ. Convers Manage. 75:498-508.

Jensen A.A., Hoffman L., Møller B.T., Schmidt A. 1997. Life cycle assessment - A guide to approaches, experiences and information sources. Environmental Issues Series, no. 6. European Environment Agency, Copenhagen, Denmark.

Kerkhof A. 2012. Life cycle-based sustainability - standards and guidelines. Pré Consultants. Available from: https://www.pre-sustainability.com/download/Life-Cycle-Based-Sustainability-StandardsGuidelines.pdf

Kim Y-J., Chung S-0., Choi C-H. 2013. Effects of gear selection of an agricultural tractor on transmission and PTO load during rotary tillage. Soil Till. Res. 134:90-6.

Lacour S., Burgun C., Perilhon C., Descombes G., Doyen V. 2014. A model to assess tractor operational efficiency from bench test data. J Terramechan. S4:1-18.

Lazzari M., Mazzetto F. 1996. A PC model for selecting multicropping farm machinery systems. Comput. Electron. Agric. 14:43-59.

Lazzari M., Mazzetto F. 2005. Prontuario di meccanica agraria e meccanizzazione. Ed. REDA, Torino, Italy.

Lindgren M., Larsson G., Hansson P.A. 2010. Evaluation of factors influencing emissions from tractors and construction equipment during realistic work operations using diesel and bio-fuels as substitute. Biosys. Eng. 107:123-30.
Meul M., Middelaar C.E., de Boer I.J.M., Van Passel S., Fremaut D., Haesaert G. 2014. Potential of life cycle assessment to support environmental decision making at commercial dairy farms. Agr. Syst. 131:105-15.

Nemecek T., Huguenin-Elie 0., Dubois D., Gaillard G., Schaller B., Chervet A. 2011. Life cycle assessment of Swiss farming systems: II. Extensive and intensive production. Agr. Syst. 104:233-45.

Nemecek T., Kägi T. 2007. Life cycle inventories of agricultural production systems. Ecoinvent report version 2.0. Editors: 0. Volume: 15. Swiss Centre for LCI, ART. Dübendorf and Zurich, Switzerland.

Niero M., Ingvordsen C.H., Peltonen-Sainio P., Jalli M., Lyngkjær M.F., Hauschild M.Z., Jørgensen R.B. 2015. Eco-efficient production of spring barley in a changed climate: A Life Cycle Assessment including primary data from future climate scenarios. Agric. Syst. 136:46-60.

Notarnicola B., Salomone R., Petti L., Renzulli P.A., Roma R., Cerutti A.K. 2015. Life cycle assessment in the agri-food sector. Springer, Milan, Italy.

OECD (Organisation for Economic Co-operation and Development). Reports Code 2. 2010 - 2012.

Ossés de Eicker M., Hischier R., Kulay L.A., Lehmann M., Zah R., Hurni, H. 2010. The applicability of non-local LCI data for LCA. Environ. Impact Assess. Rev. 30:192-9.

Reboul C., 1964. Temps des travaux et jours disponibles en agriculture. Official document of CIOSTA Institute. Economie Rurale 61:50-80.

Rotz C.A., Muhtar H.A, Black J.R. 1983. A multiple crop machinery selection algorithm. Trans. ASAE 26:1644-9.

Schäffeler U., Keller M. 2008. Non-road fuel consumption and pollutant emissions. Study for the period from 1980 to 2020. Environmental studies no. 0828. Federal Office for the Environment, Bern, Switzerland.

Serrano J.M., Peça J.O., da Silva J.M., Pinheiro A., Carvalho M. 2007. Tractor energy requirements in disc harrow systems. Biosyst. Eng. 98:286-96.

Siemens J., Hamburg K., Tyrrell T. 1990. A farm machinery selection and management program. J. Prod. Agric. 3:212-9.

Søgaard H., Sørensen C.G. 1996. A model for optimal selection of machinery sizes within the farm machinery system. pp 588-596 in 6th Int. Conf. on Computers in Agriculture, American Society of Agricultural Engineers, St. Joseph, MI, USA.

Sørensen C.G., Halberg N., Ousdhoorn F.W., Petersen B.M., Dalgaard R. 2014. Energy inputs and GHG emissions of tillage systems. Biosyst. Eng. 120:2-14.

Tendall D.M., Gaillard G. 2015. Environmental consequences of adaptation to climate change in Swiss agriculture: an analysis at farm level. Agr. Syst. 132:40-51. 


\section{Glossary}

\section{Engine parameters}

Maximum power

Power absorbed by the implement

Power at the minimum specific fuel consumption

Minimum specific fuel consumption

Engine load

Engine load at the minimum specific fuel consumption

Tractor (TR)

Forward speed

Global efficiency

Traction force

Traction power

Power at PT0

Weight/power ratio

Adherence weight

Adherence coefficient

Ballasting

Power surplus coefficient

Pitch distance

Length of parallels on three-point hitch till tractor rear axle Distance between TR's journal boxes and 0M's centre of gravity

Mass

Maximum lifted weight

Implement (OM)

Working depth

Working width
Rolling coefficient

Effective field capacity

EFC ha $h^{-1}$

$\begin{array}{cc}\mathrm{Pm}_{\text {MAX }} & \mathrm{kW} \\ \mathrm{Pm}^{*} & \mathrm{~kW} \\ \mathrm{Pm}_{\mathrm{csmin}} & \mathrm{kW} \\ \mathrm{Cs}_{\min } & \mathrm{g} \cdot \mathrm{kWh}^{-1} \\ \lambda & \% \\ \lambda_{0} & \%\end{array}$

Field and working time components

Surface

Total time for fieldwork operations

Effective time

Turns time

Filling-emptying time

On-field maintenance time (regulations)

Avoidable downtime (working disorganisation)

Unavoidable downtime (sudden breakings)

On-farm preparation time (coupling/ uncoupling)

On-field preparation time (arrange the working layout)

Rest time

Transfer time

Physical lifetime

Materials consumption and emissions

Amount of machine (TR and OM)

Emissions

Specific combustion gases emissions

Fuel consumption

Lubricant retention time

Lubricant consumption

Tire lifetime

Tire mass

Ratio between tire and tractor lifetime

$\begin{array}{cc}\text { A } & \text { ha } \\ \text { T } & \text { h } \\ \text { TEF } & \mathrm{h} \\ \text { TAV } & \mathrm{h} \\ \text { TAS } & \mathrm{h} \\ \text { TAC } & \mathrm{h} \\ \text { TME } & \mathrm{h} \\ \text { TMI } & \mathrm{h} \\ \text { TPH } & \mathrm{h} \\ \text { TPL } & \mathrm{h} \\ \text { TRE } & \mathrm{h} \\ \text { TRI } & \mathrm{h} \\ \text { PL } & \mathrm{h}\end{array}$

AM $\mathrm{kg} \cdot \mathrm{ha}^{-1}$

EM g

$\mathrm{EM}_{\mathrm{SP}} \mathrm{g} \cdot \mathrm{kWh}^{-1}$

FC $\mathrm{kg} \cdot \mathrm{ha}^{-1}$

$\mathrm{T}_{\mathrm{r}} \quad \mathrm{h}$

LC $\mathrm{kg} \cdot \mathrm{ha}^{-1}$

$\mathrm{h}_{\mathrm{PN}} \mathrm{h}$

$\mathrm{m}_{\mathrm{PN}} \quad \mathrm{kg}$

$\mathrm{k}_{\mathrm{h}} \quad \%$ 